\title{
Non-Surgical Pneumoperitoneum Complicating Mechanical Ventilation
}

\author{
Youssef Motiaa*, wafae El Otmani, Nadia Boutayeb, Brahim Elahmadi, Abdelilah Ghannam and Zakaria Houssein \\ Belkhadir
}

National Institute of Oncology, department of anesthesiology and intensive care, and Palliative care unit Ibn Sina university hospital, Faculty of Medicine and Pharmacy, Mohammed V University, Rabat, Morocco

Received: 笽April 19, 2018; Published: 鲇 April 30, 2018

*Corresponding author: Youssef Motiaa, Anesthesiology and Intensive Care Department Ibn Sina University Hospital, Faculty of Medicine and Pharmacy, Mohammed V University Rabat, Morocco

\begin{abstract}
The occurrence of a pneumoperitoneum is usually linked to intra-abdominal hollow-organ perforation and generally requires emergency abdominal surgery. In 5 to $15 \%$ of cases, the pneumoperitoneum is not related to organ perforation and could be caused by various aetiologies. Barotrauma secondary to either invasive or non invasive mechanical ventilation can cause a pneumomediastinum with air diffusion to retroperitoneum and peritoneal cavity with extensive subcutaneous emphysema. We present a case of a fifty-six-year-old patient with a permanent tracheostomy for oropharyngeal neoplasm, admitted to Intensive Care Unit (ICU) for severe pneumonia requiring mechanical ventilation leading to pneumoperitoneum and retropneumoperitoneum with extensive subcutaneous emphysema. We also discuss Investigations and management challenges for this patient.
\end{abstract}

Keywords: Mechanicalventilation; Barotraumas; Pneumoperitoneum; Retropneumo-peritoneum; Conservative Management

Abbreviations: ICU: Intensive Care Unit; CT: Commuted Tomography

\section{Introduction}

Pneumoperitoneum is the presence of air in peritoneal cavity. Chest x-ray commonly reveals a subdiaphragmatic crescent of air. It is due to hollow-organ perforation in 85 to $95 \%$ of cases. Other aetiologies of pneumoperitoneum do not require emergency surgical exploration [1,2]. Presence of gas in peritoneal cavity without bowel perforation is called spontaneous pneumoperitoneum that results from thoracic, abdominal or pelvic causes [3]. Mechanical ventilation can cause a pneumoperitoneum during ventilator induced barotrauma which is usually revealed by subcutaneous emphysema. We report the case of a non-surgical pneumoperitoneum and retroperitoneum, in a patient with permanent tracheostomy for pharyngeal cancer, that occured after mechanical ventilation and favorable clinical outcome with conservative management.

\section{Case report}

A 56-year-old with permanent tracheostomy for hypopharyngeal cancer on radiotherapy was admitted to ICU for community acquired pneumonia with septic shock. She required mechanical ventilation via tracheostomy, broad spectrum antibi otics and she was started on vasopressors (Noradrenalin) through righ internal jugular central venous catheter. Mechanical ventilation was undertaken with Assist Control Ventilation, a tidal volume of $6 \mathrm{ml} / \mathrm{kg}$ ideal body weight, a respiratory rate of 12 cycles $/ \mathrm{min}$, a positive end expiratory pressure of $6 \mathrm{~cm} \mathrm{H}_{2} \mathrm{O}$ and $\mathrm{FiO}_{2}$ of $60 \%$, the patient was sedated with propofol and remifentanyl. 24 hours later, examination revealed extensive subcutaeous emphysema to chest wall and abdomen, peak pressures were normal and breath sounds were equally transmitted on auscultation. The chest x-ray did not show any pneumothorax but revealed obvious bilateral crescent of air beneath diaphragm compatible with pneumoperitoneum (Figure 1). Haemodynamically, the patient improved and vasopressors were stopped 30 hours later despite the pneumoperitoneum. Thoraco-abdominal Commuted Tomography (CT) scan confirmed the pneumoperitoneum, revealed a retropneumoperitoneum, pneumomediastinum and ruled out a pneumothorax (Figure 2). Investigation was completed by a gastrograffin enema that was injected through the gastrostomy tube inserted before the start of radiotherapy, and did not reveal leakage from the digestive tract. 
Conservative management was adopted as the patient was clinically improving, she was weaned of vasopressors and mechanical ventilation 5 days later, subcutaneous emphysema and abdominal distension steadily resolved and the patient was discharged to medical ward after 10 days stag in ICU.
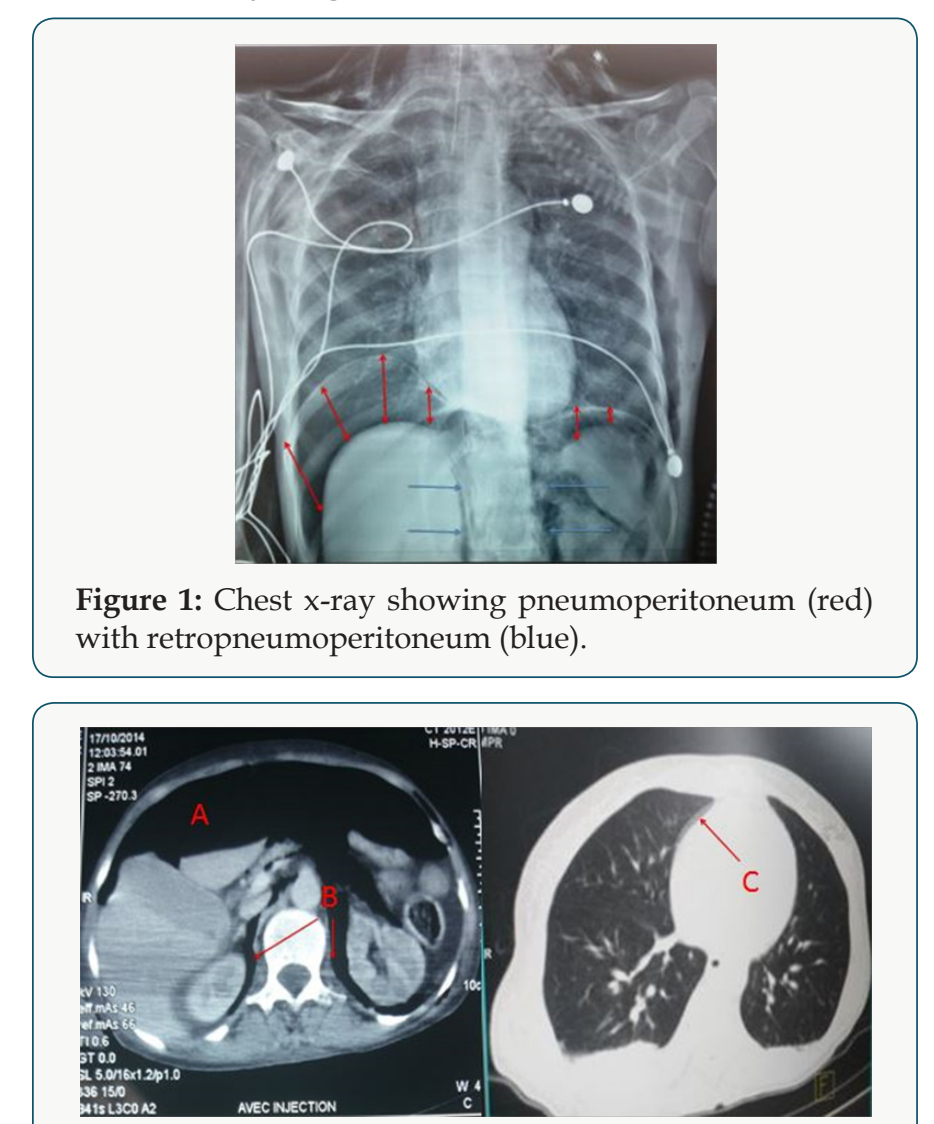

Figure 2: CT showing pneumoperitoneum (A) retropneumoperitoneum (B) with pneumomediastinum (C).

\section{Discussion}

Pneumoperitoneum is an uncommon complication of mechanical ventilation and its causes need to be correctly diagnosed to avoid unnecessary laparotomy. Non-surgical pneumoperitoneum is the presence of air in the peritoneal cavity and is usually detected on chest $\mathrm{x}$-ray, but its management is controversial based on observation or laparotomy [4]. According to Mularskei, there are five main causes of non-surgical pneumoperitoneum: False or pseudo-pneumoperitoneum describes a similar radiological aspect of a pneumoperitoneum but can be caused by a pulmonary atelectasis simulating the aspect of air beneath the diaphragm, subphrenic extraperitoneal fat or interposition of the right hepatic lobe to the diaphragm [5,6]. Abdominal causes: abdominal surgery [7], peritoneal dialysis $[8,9]$, gastro-intestinal explorations $[10,11]$, colonoscopy $[12,13]$ Thoracic causes: mechanical ventilation, cardio-pulmonary resuscitation, pneumothorax. Gynaecologic causes: Hysterosalpingography, pelvic inflammatory diseases by air diffusion into the peritoneal cavity via the uterus and the Fallopian tubes Other causes: Scleroderma, dental extraction, cocaine and idiopathic [3].
In this case, investigations including thoraco-abdominal CT, oeso-gastro-duodenal endoscopy and digestive opacification with gastrografin enema ruled out a hollow-organ perforation and indication for emergency laparotomy. The CT has revealed a pneumomediastinum without pneumothorax, likely caused by a barotrauma with subsequent retroperitoneum and pneumoperitoneum. This can be explained by the passage of air by a number of routes. Mediastinal air my pass directly through micro-perforations of the pleura and diaphragm or via thoracoabdominal communicating pores to the retro-peritoneum and then the peritoneal cavity [3]. Pneumoperitoneum can also occur as a complication of non-invasive ventilation [14] or following multiple laryngoscopies in difficult intubation [15]. Predictive factors of pneumoperitoneum during mechanical ventilation in adults include high airway pressures, ventilation with high tidal volumes, low lung compliance and underlying lung diseases such as chronic obstructive pulmonary disease or Acute Respiratory Distress Syndrom [3]. The association between high airway pressures and barotrauma is demonstrated in animals with both subcutaneous emphysema and pneumoperitoneum are induced by presures over $60 \mathrm{~cm} \mathrm{H2O} \mathrm{[16].} \mathrm{Management} \mathrm{of} \mathrm{spontaneous} \mathrm{pneumoperitoneum}$ is controversial. No consensus exists on the optimal management of non-surgical pneumoperitoneum complicating mechanical ventilation but some authors advocate conservative management when abdominal distension is minimal, absence of signs of peritonitis, absence of fever or leucocytosis and most importantly absence of surgical cause of the pneumoperitoneum [3]. In this case, pneumoperitoneum was cleared with conservative management, decision was made in consultation with the surgical team in view of the absence of abdominal cause, absence of signs of abdominal compartment syndrom and the clinical improvement of the patient [17].

\section{Conclusion}

The occurrence of subcutaneous emphysema in a patient under mechanical ventilation should raise suspicion of a pneumoperitoneum, either isolated or associated to pneumothorax or retropneumoperitoneum and a surgical cause should be ruled out. In the absence of signs of peritoneal irritation and obvious surgical cause, a non surgical cause of pneumoperitoneum in patients under mechanical ventilation should be recognised and a conservative management adopted to avoid unnecessary laparotomies.

\section{References}

1. McGlone FB, Vivion CG, Meir L (1966) Spontaneous pneumoperitoneum. Gastroenterology 51(3): 393-398.

2. Winek TG, Mosely HS, Grout G (1988) Pneumoperitoneum and its association with ruptured abdominal viscus. Arch Surg 123(6): 709-712.

3. Mularski RA, Sippel JM, Osborne ML (2000) Pneumoperitoneum: a review of nonsurgical causes. Crit Care Med 28(7): 2638-2644.

4. Mularski RA, Ciccolo ML, Rappaport WD (1999) Nonsurgical causes of pneumoperitoneum. West J Med 170(1): 41-46. 
5. Chandler JG, Berk RN, Golden GT (1977) Misleading pneumoperitoneum. Surg Gynecol Obstet 144(2): 163-174.

6. Cho KC, Baker SR (1994) Extraluminal air. Diagnosis and significance. Radiol Clin North Am 32(5): 829-844.

7. Schauer PR, Page CP, Ghiatas AA, Miller JE, Schwesinger WH, et al. (1997) Incidence and significance of subdiaphragmatic 63(2): 132-136.

8. Air following laparoscopic cholecystectomy. Am Surg 63(2): 132-136.

9. Kiefer T, Schenk U, Weber J, Eugen Hiubel, Ulrich Kuhlmann (1993) Incidence and significance of pneumoperitoneum in continuous ambulatory peritoneal dialysis. Am J Kidney Dis 22(1): 30-35.

10. Lee FT Jr, Leahy Gross KM, Hammond TG, Wakeen MJ, Zimmerman SW, et al. (1994) Pneumoperitoneum in peritoneal dialysis patients: Significance of diagnosis by CT. J Comput Assist Tomogr 18(3): 439-442.

11. Gottfried EB, Plumser AB, Clair MR (1986) Pneumoperitoneum following percutaneous endoscopic gastrostomy.A prospective study. Gastrointest Endosc 32(6): 397-399.

12. Pidala MJ, Slezak FA, Porter JA (1992) Pneumoperitoneum following percutaneous endoscopic gastrostomy: Does the timing of panendoscopy matter?. Surg Endosc 6(3): 128-129.
13. Damore LJ, Rantis PC, Vernava AM, Longo WE (1996) Colonoscopic perforations: Etiology, diagnosis, and management. Dis Colon Rectum 39(11): 1308-1314.

14. Wakeen MJ, Zimmerman SW, Bidwell D (1994) Viscus perforation in peritoneal dialysis patients: Diagnosis and outcome. Perit Dial Int 14(4): 371-377.

15. Wolfromm A, Weiss N, Espinoza S, Diehl JL, Fagon JY, et al. (2011) Noninvasive positive pressure ventilation (NIPPV)-induced pneumocephalus and pneumoperitoneum in a patient with a one-way flow control ventriculoperitoneal shunt. Intensive Care Med 37(5): 889-890.

16. Ono Y, Okubo Y, Hashimoto K, Inokuchi R, Odajima H, et al. (2015) Massive subcutaneous emphysema, bilateral pneumothorax, pneumomediastinum, pneumoperitoneum, pneumoretro-peritoneum, and pneumoscrotum after multiple direct laryngoscopies: an autopsy case report. J Anesth 29(4): 622-626.

17. Grosfeld JL, Boger D, Glatsworthy HW (1971) Hemodynamic and manometric observations in experimental air block syndrome. J Pediatr Surg 6(3): 339-344.

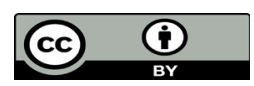

This work is licensed under Creative Commons Attribution 4.0 License

To Submit Your Article Click Here:

Submit Article

DOI: $10.32474 /$ CTGH.2018.01.000103

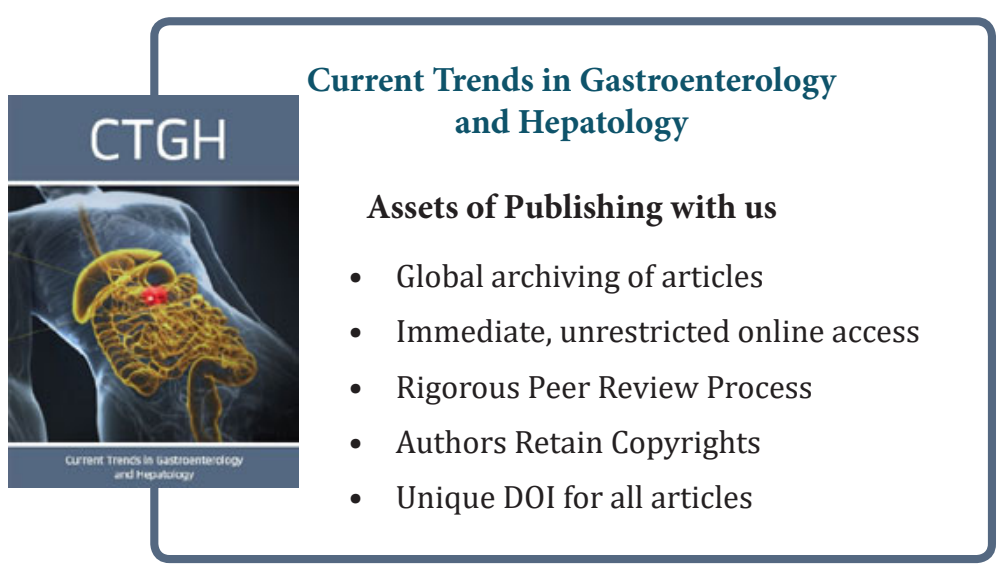

